\title{
Fine-tuning of a thermosalient phase transition by solid solutions
}

\author{
Elisa Nauha, ${ }^{[a] \neq}$ Matteo Lusi, ${ }^{\text {[a]§ }}$ Panče Naumov ${ }^{[a]}$
}

\begin{abstract}
Thermosalient crystals are solids that exhibit motion at macroscale as a consequence of a thermally induced phase transition. They represent an interesting scientific phenomenon and could be useful as actuators for the conversion of thermal energy into motion or mechanical work. The potential utilization of these miniature transducers in real-world devices requires controllable phase transition (i.e. predetermined temperature). While it is difficult to control these thermomechanical performances with a singlecomponent molecular crystal, "tunable" properties could be accomplished by using solid solutions. To verify this hypothesis, the thermosalient materials $\left[\mathrm{Zn}(\mathrm{bpy}) \mathrm{Br}_{2}\right]$ (bpy $=2,2^{\prime}$-bipyridine) was selected and its synthesis was performed in the presence of chloride ions. The resulting mixed crystals $\left(\left[\mathrm{Zn}(\mathrm{bpy}) \mathrm{Br}_{2(1-x)} \mathrm{Cl}_{2 x}\right]\right.$ ) show that the product undergoes the expected thermosalient phase transition, and temperature of the onset of the phase transition and the transition enthalpy depend on the $\mathrm{Cl} / \mathrm{Br}$-ratio.
\end{abstract}

One of the goals of the materials science is to establish methods for the design and fabrication of functional materials, the performance of which can be easily optimized for the intended application(s). In molecular materials, the physicochemical properties can be controlled, at least in principle, at various levels of structural hierarchy. In some cases (e.g., pharmaceuticals and dyes) this optimization can be accomplished by adjusting the formulation of the final product (excipients, particle size and shape, etc.)..$^{[1]}$ When this approach is not viable, a more demanding chemical modification of the constituents of the material is required. Alternatively, some material properties can be modified by changing the way molecules are ordered and interact in the solid state. To alter those properties, which are intrinsic to the solid structure, a change in molecular packing is required..$^{[2]}$ In single-component and stoichiometric multicomponent crystals (cocrystals, hydrates, etc.), this crystal engineering ${ }^{[3]}$ (or supramolecular) approach has proved successful in many instances ${ }^{[4]}$ although generally it remains impossible to predict the properties of the modified material. On the contrary, in non-stoichiometric multicomponent crystals (solid solutions) the structure and properties vary regularly and can be "tuned" by controlling the composition. ${ }^{[5]}$ Indeed, from the crystal engineering point of view, solid solutions of molecular systems have enabled, among other things, modulation of crystal structure and phase transition

[a] Dr. Elisa Nauha, Dr. Matteo Lusi, Prof. Panče Naumov New York University Abu Dhabi PO Box 129188

Abu Dhabi, United Arab Emirates

E-mail: matteo.lusi@ul.ie

* Current address: School of Chemistry, Joseph Banks Laboratories University of Lincoln, Lincoln, UK.

$\S \quad$ Current address: Department of Chemical and Environmental Science, University of Limerick. Limerick, Ireland

† Electronic supplementary information (ESI) available: Experimental procedures, crystallographic data, PXRD and supplementary figures and video. CCDC 1469392-1469405. temperatures ${ }^{[6]}$ (including melting point), ${ }^{[7]}$ as well as optical, ${ }^{[8]}$ electronic, ${ }^{[9]}$ mechanical| ${ }^{[10]}$ and physisorption ${ }^{[11]}$ properties.

Here, we set as our goal to attain control over the mechanical response from thermosalient crystals, ${ }^{[12]}$ an emerging class of exotic materials that exhibit swift motions at a macroscale as a result of very fast structural phase transitions. These materials - and their photochemical counterparts (photosalient crystals) ${ }^{[13]}$ - are capable of converting external energy into mechanical work, and could be useful as miniature energy-to-motion transducers in macroscopic actuating devices. The projected applications of the salient phenomena require deeper understanding of the related structure-property relationships, as well as better control over their thermal properties and the related dynamics. This task is particularly challenging since the thermosalient phenomenon is a collective result of thermodynamic and kinetic factors.

In the continuous effort to understand the behaviour of this class of materials a series of mixed crystal analogues of the tetrahedral complex $\left[\mathrm{Zn}(\mathrm{bpy}) \mathrm{Br}_{2}\right]\left(\mathbf{1}_{1}\right)^{[14]}$ was prepared. When cooled below $230 \mathrm{~K}$, monoclinic crystals of $\mathbf{1 1}$ undergo a thermosalient phase transition to a triclinic form. This effect is uncommon because most of the hitherto reported thermosalient phenomena occur above room temperature and are isosymmetric (i.e. the crystal symmetry is retained). ${ }^{[12]}$ The chloride analogue of $\mathbf{1 1}_{1},\left[\mathrm{Zn}(\mathrm{bpy}) \mathrm{Cl}_{2}\right](\mathbf{1 0})$, is only known as a triclinic form that is isomorphous to the low-temperature (LT) form of $1_{1} \cdot{ }^{[15]}$ It is well known that chloride and bromide analogues can form substitutional mixed crystals, ${ }^{[16]}$ which prompted us to synthesize binary mixed crystals. It should be noted that at a molecular level the mixed crystals $\left(\mathbf{1}_{\boldsymbol{x}}\right)$, with general formula $\left[\mathrm{Zn}(\mathrm{bpy}) \mathrm{Br}_{2 x} \mathrm{Cl}_{2(1-x)}\right]$ are in fact a threecomponent solid solution of $\left[\mathrm{Zn}(\mathrm{bpy}) \mathrm{Cl}_{2}\right],\left[\mathrm{Zn}(\mathrm{bpy}) \mathrm{Br}_{2}\right]$, and [Zn(bpy)BrCl].

Single crystals were prepared by solvent evaporation of solutions containing bpy and varying ratio of $\mathrm{ZnCl}_{2}$ and $\mathrm{ZnBr}_{2}$ (for details, see ESI). Alternatively, a polycrystalline mixture of phases can be obtained by manual grinding of the reagents (Figure S2). Single crystal X-ray diffraction (XRD) at room temperature confirmed the formation of both the monoclinic and triclinic forms. On cooling to $100 \mathrm{~K}$ all monoclinic forms convert to triclinic. Structure refinement allowed the determination of the $\mathrm{Br} / \mathrm{Cl}$ ratio in each crystal. Multiple crystals within the same vial showed that the halide composition varied over a relative narrow range (+/- 5\%) suggesting that the solid solution is almost ideal. In all investigated solvent systems, $\mathrm{Zn}(\mathrm{bpy}) \mathrm{Cl}_{2}$ was less soluble than $\mathrm{Zn}(\mathrm{bpy}) \mathrm{Br}_{2}$; as a result the low bromine content crystals of $\mathbf{1}_{\boldsymbol{x}}$ crystallized out of the solutions first. 


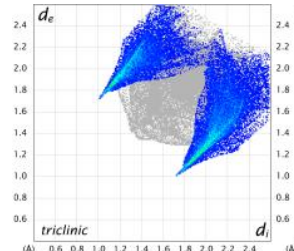

a)

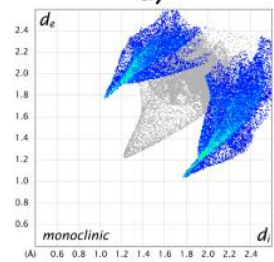

d)

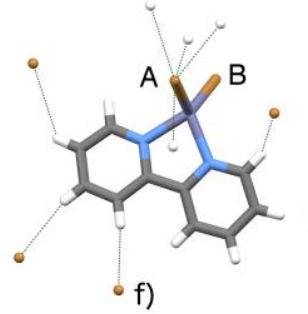

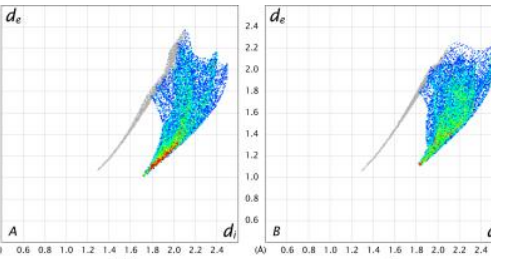

b)

c) e)

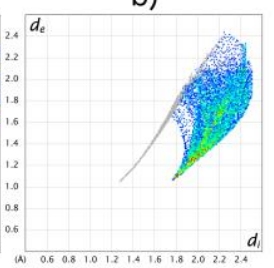

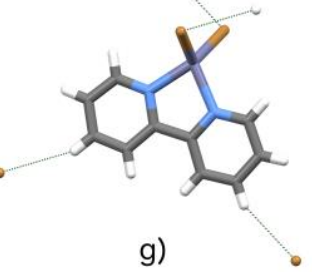

Figure 1. Interactions in the crystal structures of $\mathrm{Zn}(\mathrm{bpy}) \mathrm{Br}_{2 x} \mathrm{Cl}_{2(1-}$ $x)$ ]. (a-e) Fingerprint plots of the Hirshfeld surfaces drawn for the entire molecules $(a, d)$ and for the individual bromine atoms $(b, c, e)$ with the contacts to hydrogen atoms highlighted. Stick-style representation of the (f) triclinic $(100 \mathrm{~K})$ and $(\mathrm{g})$ monoclinic phase $(320 \mathrm{~K})$ showing $\mathrm{Br}$-to-H contacts shorter than the sum of the van der Waals radii corrected by $0.04 \AA$.

In the triclinic crystals, the halide occupies two nonequivalent positions, each favouring a particular ion: Hirshfeld surface analysis ${ }^{[17]}$ indicates that the chloride preferably occupies the more sterically hindered site: the one that makes shorter contacts to neighbouring molecules (Figure 1). Notably, the difference in halide occupancy between the two positions is as high as $50 \%$ (see $\mathbf{1}_{\mathbf{0 . 1}}$ and $\mathbf{1}_{\mathbf{0 . 3}}$ ). On the other hand, in the monoclinic form the halide positions are symmetry-related and hence indistinguishable by XRD. Thus, the choice of the monoclinic symmetry enforces equal relative occupancy of the halides in the two sites. However, when a monoclinic crystal is cooled below the transition temperature to $100 \mathrm{~K}$, the $\mathrm{Br} / \mathrm{Cl}$ ratio of the two sites in the triclinic crystal differ inasmuch as $10 \%$ (see 10.7). We believe this occupational disorder exists also in the monoclinic phases but cannot be modelled due do the symmetry constrains. Alternatively, it should be assumed that the difference in occupancy results from halide migration during the phase transition. ${ }^{[18]}$

Only solid solutions with $\mathrm{Br} / \mathrm{Cl}$ ratio above $~ 70 \%$ crystallize from solution at room temperature in the monoclinic form and exhibit the phase transition at low temperature. For lower bromide concentrations, room temperature XRD results in the triclinic form. However, triclinic crystals with lower bromine content, convert to the monoclinic form upon heating (above $\sim 360 \mathrm{~K}$ ). In our experiments the concentration limit to obtain the monoclinic form was $\sim 50 \%\left(\mathbf{1}_{0.5}\right)$. It must be noted that crystals with higher bromine content $(80 \%$ and $90 \%)$ appear of better quality relative to those with lower bromine content (ESI Figure $\mathrm{S} 1$ and Video) making the characterization of the latter more difficult. This trend is likely related to the lower solubility of $\left[\mathrm{Zn}(\mathrm{bpy}) \mathrm{Cl}_{2}\right]$, resulting in faster crystallization.

In agreement with Vegard's law, ${ }^{[19]}$ the unit cell axes and the volume of $\mathbf{1}_{\boldsymbol{x}}$ at $100 \mathrm{~K}$ (in the triclinic form) increase with increasing bromine content (Figure 2 and ESI Figure S3). The angle $\alpha$ increases from $112.8^{\circ}$ in $\mathbf{1}_{0}$ to $114.7^{\circ}$ in $\mathbf{1}_{1}$. The variation

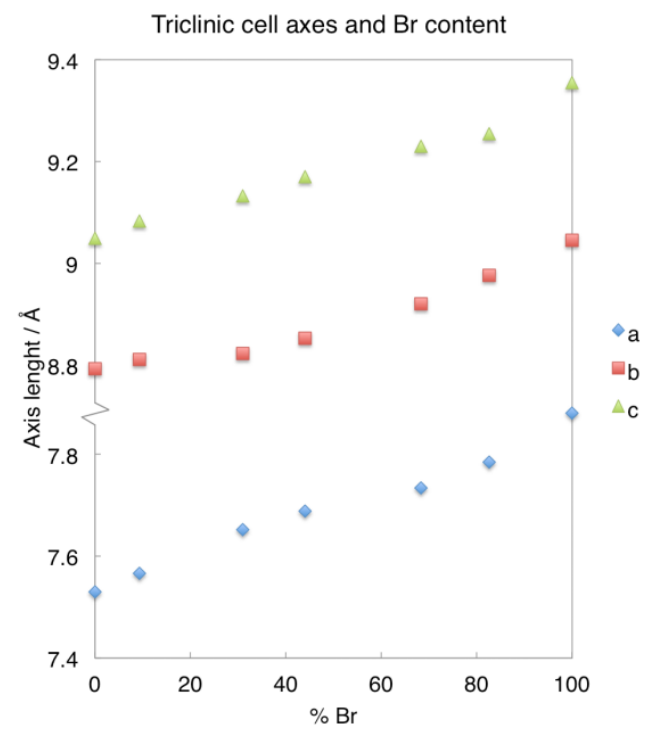

Figure 2. Relationship between the cell metrics and the bromine content in the triclinic structures of $1 \mathrm{x}$ at $100 \mathrm{~K}$ (the error bars are smaller than the markers).

of the cell dimensions is less pronounced for the monoclinic phases at $320 \mathrm{~K}$ (ESI Figure S4).

As expected, the monoclinic-to-triclinic phase transition is thermosalient, with evident jumping of the crystals (ESI Video). Macroscopic movement also accompanies the reverse transition, but the effect is noticeably weaker. Variabletemperature diffraction studies confirm that the thermal expansion and the phase transition for mixed crystals are consistent with those of pure $\mathbf{1}_{1}$ with an average uniaxial thermal linear expansion coefficients $478 \times 10^{-6} \AA \mathrm{K}^{-1}$ for the $b$ axis and $-700 \times 10^{-6} \AA \mathrm{K}^{-1}$ for the $c$ axis of the triclinic 10.7. (see ESI Figure S5). Expectedly, the cell dimension variation is discontinuous at the phase transition. The $\alpha$ angle changes from $\sim 112^{\circ}$ to $\sim 108^{\circ}$ whereas the $\beta$ and $\gamma$ angles, as well the $b$ and $c$ axes, converge to an equal value reflecting the transformation to a monoclinic cell.

Since experimental and sample-dependent factors such as particle size, kinetics and mechanical effects can have a profound effect on the thermosalient phenomenon, ${ }^{[12]}$ the phase transition was also monitored by $\mathrm{X}$-ray powder diffraction (XRPD) from the same single crystals after they were gently
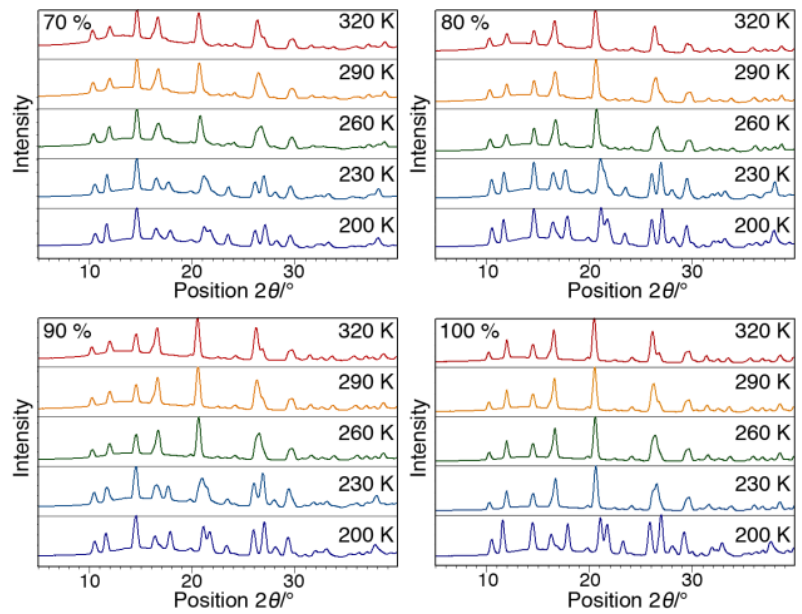

Figure 3. X-ray powder diffraction patterns of crystals of $1 \mathrm{x}$ with different composition ( $70 \%, 80 \%, 90 \%$ and $100 \%$ bromine) at variable temperatures showing the transition from monoclinic to triclinic symmetry, as indicated most clearly by doubling of the peaks around $17^{\circ}, 21^{\circ}$ and $27^{\circ}$ in $2 \theta$. 
crushed to uniform microcrystalline powder in cryoprotective oil. As shown in Figure 3, these measurements are consistent with the results observed with pristine crystals.

Notably, when differential scanning calorimetry (DSC) was employed to confirm the occurrence of the thermal event in ascrystallized crystals whose composition was assessed by XRD the transition was observed for samples containing at least $80 \%$ bromine (Figure 4). Only in one instance a weak thermal event was recorded in a sample with $70 \%$ bromine (ESI Figure S6). Also optical microscopy is unable to confirm the mechanical effect for $\mathbf{1}_{0.7}$ (ESI Video). Having excluded the particle size as the possible cause of the discrepancy, we speculate that the time scale of the experiments has an effect on the transformation. During the XRD measurement it was observed that in $\mathbf{1}_{0.5}$ the triclinic-to-monoclinic transition occurs in several minutes at $360 \mathrm{~K}$. Thus, the transition can not be detected in a typical DSC experiment or by optical microscopy (at a heating rate of 5 to $10^{\circ} \mathrm{C} \mathrm{min}^{-1}$ ).

The DSC results indicate a linear relationship between the bromine content and transition temperature (Figure 4). Also the hysteresis in the transition temperature increases with increasing bromine content (Figure 4). The molar enthalpies
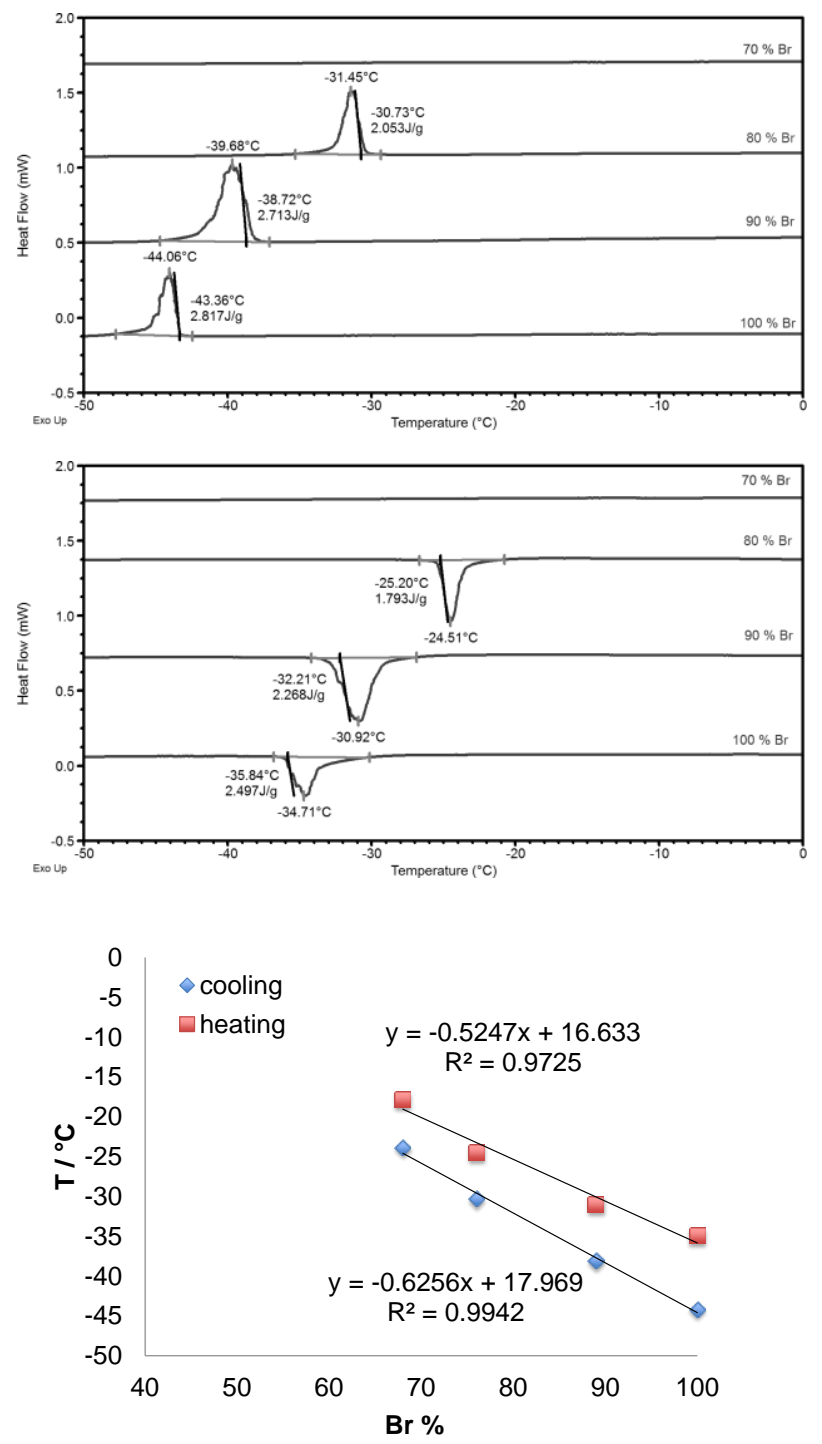

Figure 4. Thermal properties studied using DSC. Top and middle: DSC of samples with $\sim 70 \%, 80 \%, 90 \%$ and $100 \%$ bromine content (the composition here refers to the crystallizing solution) upon cooling (top) and heating (centre) showing variation of the temperature of the phase transition with the bromine content. Bottom: relation between the bromine content and transition temperature (the error bars are smaller than the markers). obtained by integration of the DSC curves for the phase transitions were $0.74(1), 1.01(1)$ and $1.07(1) \mathrm{kJ} \mathrm{mol}^{-1}$ for samples having approximately 76, 89 and 100\% bromine, respectively, indicating greater energy change during the transition with higher bromine content. Due to the thermosalient nature of the transition and the uneven profile of the thermograms, the accurate enthalpies could not be obtained by integration. However, visual evaluation of the phenomenon suggests that the crystal jumps were more pronounced when the bromine content is higher. These qualitative observations warrant further experimental evidence.

In summary, the results presented here show that the thermosalient complex $\left[\mathrm{Zn}(\mathrm{bpy}) \mathrm{Br}_{2}\right]$ forms a continuous series of solid solutions with [ $\left.\mathrm{Zn}(\mathrm{bpy}) \mathrm{Cl}_{2}\right]$ (and [ $\left.\mathrm{Zn}(\mathrm{bpy}) \mathrm{BrCl}\right]$ ). In accordance with Vegard's law ${ }^{[19]}$ the unit cell changes linearly with composition. Mixed crystals with high bromine content undergo thermosalient transition similar to that of crystals of pure $\left[\mathrm{Zn}(\mathrm{bpy}) \mathrm{Br}_{2}\right]$, while phases that are richer in chlorine behave similarly to $\left[\mathrm{Zn}(\mathrm{bpy}) \mathrm{Cl}_{2}\right]$. The temperature of the thermosalient transition correlates linearly with the $\mathrm{Br} / \mathrm{Cl}$ ratio, with higher transition temperatures corresponding to lower bromine content. Being determined by multiple factors such as crystal mosaicity, size, shape and position, as well as by the temperature variation, the incongruous mechanical response from the crystals during the thermosalient effect prevented the quantification of its magnitude. The results are suggestive that the high bromine content in the sterically constrained crystallographic site triggers the phenomenon. In the quest to prepare heat-to-motion transducers a deeper understanding of the thermosalient mechanism is required. Moreover for future applications, precise control of the salient effect (the onset temperature and magnitude) is of fundamental importance. In this view the fine-tuning of the thermomechanical properties of the product by using solid solutions will not only provide insight into the structure-property relationships, but it could also be helpful to "engineer" these exotic materials.

\section{Acknowledgements}

This work was sponsored by a grant from NYU Abu Dhabi. We thank J. Bernstein for the discussions and advice.

Keywords: mechanical effects $\cdot$ mixed crystals $\bullet$ solid solutions $\bullet$ thermosalient effect

[1] D. A. Shah, S. B. Murdande, R. H. Dave, J. Pharm. Sci. 2015, 10-24.

[2] J. Bernstein, Polymorphism in Molecular Crystals, First ed., Oxford, 2007.

[3] a) G. R. Desiraju, Crystal Engineering: The Design of Organic Solids, Elsevier, 1989; b) D. Braga, F. Grepioni, G. R. Desiraju, Chem. Rev. 1998, 98, 1375-1405.

[4] a) O. Almarsson, M. J. Zaworotko, Chem. Commun. 2004, 1889-1896; b) W. Jones, W. D. S. Motherwell, A. V. Trask, MRS Bull. 2006, 31, 875-879; c) C. B. Aakeroy, N. R. Champness, C. Janiak, CrystEngComm 2010, 12, 22-43.

[5] A. I. Kitaigorodsky, Mixed crystals, Vol. 33, Springer Verlag, Berlin, 1984.

[6] a) C. J. Adams, A. L. Gillon, M. Lusi, A. G. Orpen, CrystEngComm 2010, 12, 4403-4409; b) A. Delori, P. Maclure, 
R. M. Bhardwaj, A. Johnston, A. J. Florence, O. B. Sutcliffe, I.

D. H. Oswald, CrystEngComm 2014, 16, 5827-5831.

[7] a) M. Lusi, I. J. Vitorica-Yrezabal, M. J. Zaworotko, Cryst. Growth Des. 2015; b) E. Schur, E. Nauha, M. Lusi, J. Bernstein, Chem. Eur. J. 2015, 21, 1735-1742.

[8] a) T. Wüst, J. Hulliger, J. Phys. Chem. Solids 2006, 67, 2517-2527; bT. F. W. Barth, Am. J. Sci. 1930, Series 5 Vol. 19, 135-146; c) L. Kuroki, S. Takami, K. Shibata, M. Irie, Chem. Commun. 2005, 6005-6007.

[9] M. D. Ward, Organometallics 1987, 6, 754-762.

[10] M. K. Mishra, U. Ramamurty, G. R. Desiraju, J. Am. Chem. Soc. 2015, 137, 1794-1797.

[11] a) H. Deng, C. J. Doonan, H. Furukawa, R. B. Ferreira, J. Towne, C. B. Knobler, B. Wang, O. M. Yaghi, Science 2010, 327, 846-850; b) T. Fukushima, S. Horike, Y. Inubushi, K. Nakagawa, Y. Kubota, M. Takata, S. Kitagawa, Angew. Chem. Int. Ed. Engl. 2010, 49, 4820-4824; c) A. D. Burrows, CrystEngComm 2011, 13, 3623-3642; d) E. Batisai, M. Lusi, T. Jacobs, L. J. Barbour, Chem. Commun. 2012, 48, 12171-12173; e) T. Hasell, S. Y. Chong, M. Schmidtmann, D. J. Adams, A. I. Cooper, Angew. Chem. Int. Ed. Engl. 2012, 51, 7154-7157.

[12] a) Ž. Skoko, S. Zamir, P. Naumov, J. Bernstein, J. Am. Chem. Soc. 2010, 132, 14191-14202; b) S. Chandra Sahoo, N. K. Nath, L. Zhang, M. H. Semreen, T. H. Al-Tel, P. Naumov, RSC Adv. 2014, 4, 7640-7647; c) P. Naumov, S. Chizhik, M. K. Panda, N. K. Nath, E. Boldyreva, Chem. Rev. 2015, 115, 1244012490.

[13] a) N. K. Nath, M. K. Panda, S. C. Sahoo, P. Naumov, CrystEngComm 2014, 16, 1850-1858; b) R. Medishetty, S. C. Sahoo, C. E. Mulijanto, P. Naumov, J. J. Vittal, Chem. Mater. 2015, 27, 1821-1829.

[14] M. Lusi, J. Bernstein, Chem. Commun. 2013, 49, 9293-9295.

[15] M. A. Khan, D. G. Tuck, Acta Crystallogr. Sect. C 1984, 40, 60-62.

[16] a) N. N. Nagornov, Z. physik. Chem. 1911, 75, 578584; b) C. R. Theocharis, G. R. Desiraju, W. Jones, J. Am. Chem. Soc. 1984, 106, 3606-3609; c) C. J. Adams, M. F. Haddow, M. Lusi, A. G. Orpen, Proc. Natl. Acad. Sci USA 2010, 107, 16033-16038.

[17] M. A. Spackman, D. Jayatilaka, CrystEngComm 2009, 11, 19-32.

[18] G. Mínguez Espallargas, J. van de Streek, P. Fernandes, A. J. Florence, M. Brunelli, K. Shankland, L. Brammer, Angew. Chem. Int. Ed. Engl. 2010, 49, 8892-8896.

[19] a) L. Vegard, H. Schjelderup, Phys. Z. 1917, 18, 9396; b) G. A. Crundwell, B. A. Cowans, J. A. Hopkins, J. B. Grutzner, B. Kahr, J. Solid State Chem. 1999, 145, 327-335. 